\title{
Genetic structure of the Marseilles cat population: is there really a strong founder effect?
}

\author{
M Ruiz-Garcia ${ }^{1 * 2}$ \\ 1 Instituto de genetica, Universidad de Los Andes, \\ calle 18 Carrera 1E, Bogota DC, Colombia; \\ ${ }^{2}$ Gigeem avd virgen Montserrat, 207, sexto primera, Barcelona, 08026, Spain
}

(Received 4 February 1992; accepted 21 December 1993)

Summary - In a previous study on the Marseilles cat population it was concluded that the small cat colonies were subject to a strong founder effect. A more detailed study with the $G_{\mathrm{ST}}$ and $F_{\mathrm{ST}}$ (genetic diversity) statistics and with a spatial autocorrelation analysis shows that, for the $a$ (non-agouti) and $t^{b}$ (blotched) genes, there is neither significant heterogeneity nor spatial autocorrelation. This is probably due to an appreciable gene flow throughout Marseilles (although a uniform selection pressure in favour of these alleles cannot be totally ruled out). The $O$ (orange) allele does not show spatial autocorrelation either, but it does show significant heterogeneity, which could have been caused by the late introduction of this allele into the population, coming from populations with low $O$ frequencies in a sporadic and irregular way (although the influence of diversifying selection cannot be completely ruled out). Only this allele $O$ might be influenced by a strong founder effect as stated previously. However, the $a$ and $t^{b}$ data do not support the hypothesis of a strong founder effect in these cat colonies.

cat / genetic structure / founder effect / gene flow / spatial autocorrelation

Résumé - Structure génétique de la population des chats marseillais : y a-t-il réellement un fort effet fondateur? Dans une étude précédente sur la population des chats marseillais, il avait été conclu que les petites colonies de chats étaient soumises à un fort effet fondateur. Une étude plus détaillée, à l'aide des statistiques $G_{\mathrm{ST}}$ et $F_{\mathrm{ST}}$ (diversité génétique) et d'une analyse d'autocorrélation spatiale, a montré que, pour les allèles a (non agouti) et $\mathrm{t}^{b}$ (tigré), il n'existe ni hétérogénéité significative ni autocorrélation spatiale. Ceci est probablement dî au fux important de gènes dans toute l'étendue de Marseille (bien qu'on ne puisse pas totalement écarter une pression uniforme de sélection en faveur de ces allèles). L'allèle $O$ (orange) ne montre pas non plus d'autocorrélation spatiale, mais il présente une hétérogénéité significative, qui pourrait bien avoir été produite par l'arrivée

* Correspondence and reprints. 
tardive de cet allèle dans la population, provenant de manière sporadique et irrégulière de populations à faibles fréquences de $O$ (quoique l'influence d'une sélection diversificatrice ne puisse pas être complètement exclue). Seul ce gène $O$ pourrait être soumis à une forte influence de l'effet fondateur. Cependant les données relatives aux allèles a et $\mathrm{t}^{b}$ ne confirment pas l'influence d'un important effet fondateur dans ces colonies de chats marseillais.

chat / structure génétique / effet fondateur / flux génique / autocorrélation spatiale

\section{INTRODUCTION}

Dreux (1975) analysed the genetic composition of the Marseilles cat population. Having studied the distribution of the allele frequencies for 3 coat colour genes $\left(O\right.$ (orange), $a$ (non-agouti), $t^{b}$ (blotched)) among a series of small cat colonies throughout this French town, he concluded with the following statements: "... A certain number of small semi-wild cat colonies have been observed and it is found that they are relatively isolated from one another; the great differences between the gene frequencies among the colonies are attributed to the influence of a strong founder effect..."; “... The gene frequencies are very variable and certainly show an important influence of founder effect at the moment of constitution of these isolated colonies...". However, a more detailed study of the distribution of these gene frequencies among Marseilles cat colonies, through some genetic differentiation statistics and by means of a spatial autocorrelation analysis applied to these 3 genes and to the expected heterozygosity, seems to show that the Dreux (1975) conclusion is not entirely justified.

Moreover, this study gives us an interesting opportunity to study the genetic structure of the cat colonies within a town at a microgeographical level, which will no doubt reflect the interaction of the size of the population, the gene flow, the reproductive systems and the human interferences in this species (Eanes and Koehn, 1978; Gaines and Whittam, 1980; Patton and Feder, 1981; Chesser, 1983; Gyllensten, 1985; Kennedy et al, 1987).

\section{MATERIALS AND METHODS}

Dreux (1975) showed a map of Marseilles (fig 1), where he situated 9 cat colonies studied from a genetic viewpoint. The sizes of these small colonies range from 8 to 72 cats with a mean of 19.88 cats. Together with this map, the gene frequencies for $O, a$ and $t^{b}$ alleles in these cat colonies are summarized.

\section{Genic diversity analysis}

A genic diversity analysis (Nei, 1973, 1975) has been applied to the 3 alleles above to observe whether the contribution to the genic diversity for each of these alleles is the same, or whether they show a differential genic diversity. For this, the following statistics were calculated: $G_{\mathrm{ST}}$ (gene differentiation between populations relative 


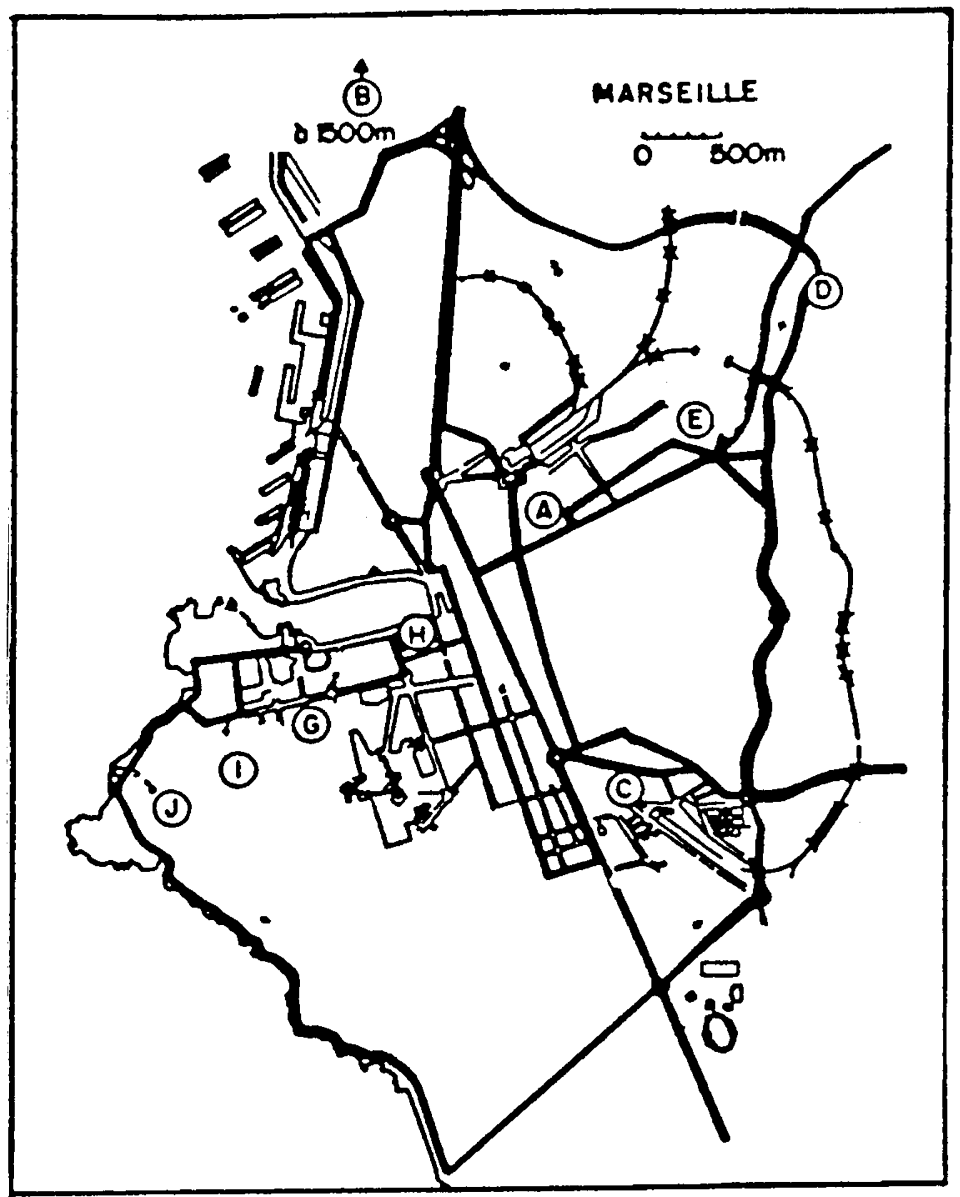

\begin{tabular}{lrrrc} 
Colony & Sample size & $p(\mathrm{O})$ & $q(\mathrm{a})$ & $q\left(\mathrm{t}^{\mathrm{b}}\right)$ \\
\hline $\mathrm{A}$ & 17 & 0.28 & 0.68 & 0.95 \\
$\mathrm{~B}$ & 11 & 0.00 & 0.84 & $?$ \\
$\mathrm{C}$ & 15 & 0.09 & 0.84 & 0.71 \\
$\mathrm{D}$ & 9 & 0.21 & 0.84 & 0.87 \\
$\mathrm{E}$ & 72 & 0.01 & 0.70 & 0.69 \\
$\mathrm{G}$ & 11 & 0.00 & 0.74 & $?$ \\
$\mathrm{H}$ & 8 & 0.38 & 0.84 & 1.00 \\
$\mathrm{I}$ & 17 & 0.30 & 0.76 & 0.77 \\
J & 19 & 0.41 & 0.82 & 0.78 \\
Total & 179 & & & \\
\hline
\end{tabular}

Fig 1. Map of Marseilles with the cat colonies studied by Dreux (1975) and gene frequencies for the $O, a$ and $t^{b}$ alleles. 
to the gene diversity in the total population), $R_{\mathrm{ST}}$ (interpopulation gene diversity relative to the intrapopulation gene diversity), $\mathrm{Dm}$ (absolute interpopulational gene diversity). The Wright's $F_{\mathrm{ST}}(1951,1965)$ has also been calculated. If there are only 2 alleles at a locus, $G_{\mathrm{ST}}$ is identical to $F_{\mathrm{ST}}(\mathrm{Nei}, 1973)$ as is the case in this study. I have calculated $F_{\mathrm{ST}}^{\prime}=F_{\mathrm{ST}}-\left(1 / 2 N_{t}\right)$ (Workman and Niswander, 1970), which is the estimate of genetic heterogeneity between populations corrected for sampling error, where $N_{t}$ is the total sample size. $F_{\mathrm{ST}}^{\prime}$ is directly related to the chi-squared statistic $\chi^{2}=2 N_{t} F_{\mathrm{ST}}^{\prime}(k-1)$ with $(k-1)(s-1)$ degrees of freedom, where $s$ is the number of populations studied and $k$ is the number of alleles for the locus. Moreover, if sample sizes are of different magnitudes, the following expression may be used: $\chi^{2}=\left[\Sigma 2 N_{i} p_{i}^{2}-\bar{p} \Sigma 2 N_{i} \cdot p_{i}\right] / \bar{p}(1-\bar{p})$ (Snedecor and Irwin, 1933), where $N_{i}$ and $p_{i}$ are the sample size and the gene frequency in population $i$, and $\bar{p}$ is the mean gene frequency over all colonies. To determine the possible differences introduced by the genetic heterogeneity between the 3 loci studied, a Fisher-Snedecor $F$ test (Workman and Niswander, 1970) was carried out.

\section{Theoretical gene flow}

The gene flow $(\mathrm{Nm}$, the average number of immigrants entering an average deme in one generation) was calculated following the expression:

$$
\left.N m=\left[\left(1 / F_{\mathrm{ST}}^{\prime}\right)-1\right] / 4 \quad \text { (Wright, } 1943,1965\right)
$$

This equality is an estimate based on an infinite island model, where the effects of migration and genetic drift are balanced in a subdivided population. These results are similar to those produced by a 2-dimensional stepping-stone model (Crow and Aoki, 1984) although they underestimate $\mathrm{Nm}$ for a one-dimensional stepping-stone model (Slatkin, 1985a; Trexler, 1988). I have also obtained estimates of gene flow for an $n$-dimensional island model $\left(N m \alpha=\left[\left(1 / G_{\mathrm{ST}}\right)-1\right] / 4 \alpha\right.$, where $\alpha=[n /\{n-1\}]^{2}$ and $n$ is the number of populations analyzed (Slatkin, 1985b)).

\section{Study of the expected heterozygosity}

An important concept to determine the possible existence of founder effect is the study of the mean expected heterozygosity of the 3 loci throughout the diverse cat colonies (Nei, 1978). To determine the possible differences between the mean values of heterozygosity among all compared pairs of colonies, the Student's $t$ test was used. To determine if there are significant differences among all expected heterozygosity means as a single set, 2 statistical methods have been applied: an Anova and a Kruskal-Wallis $H$ test with corrections (non-parametric variance analysis).

\section{Phenetic analyses}

To study the genetic relationships between these cat colonies, 2 genetic distances were employed with clearly differentiated properties (Prevosti (1974) distance and Cavalli-Sforza and Edwards (1967) distance (Chord distance)). With the genetic distance matrices obtained using these 2 methods, I have obtained dendrograms 
with the UPGMA algorithm (Sneath and Sokal, 1973). From the dendrogram it can be seen, as a preliminary step, whether the neighbouring colonies are clustered randomly.

\section{Principal coordinates analysis}

To know the possible genetic relationships among these cat colonies in the space, a principal coordinates analysis (PCA) (Gower, 1966) was carried out with the Prevosti genetic distance matrix. A minimum length spanning tree (MST) was superimposed to detect local distortions between pairs of populations (Rohlf, 1970).

\section{Mantel test}

An analysis of correlation matrices (with linear, power, exponential and logarithmic curves) between geographic distances (in metres) and genetic distances between the cat colonies was computed with the normalized Mantel test (Mantel, 1967). A Monte-Carlo simulation, with 2000 random permutations of these matrices was applied to determine the significance of these results.

\section{Spatial autocorrelation analysis}

A technique that offers more potential to understand the possible spatial relationships among these cat colonies is spatial autocorrelation analysis (SAA). An SAA tests whether the observed value of a gene frequency at one locality is dependent on values of the same variable at neighbouring localities (Sokal and Oden, 1978a). Positive results of SAA indicate that gene frequencies at neighbouring colonies are similar, while negative SAA results show marked differences between adjacent pairs when we study the meaning of SAA at the first distance class (Sokal and Menozzi, 1982). In the present work, the Moran's I index (Moran, 1950) was used. To carry out this spatial analysis 2 different distance classes (DCs) were used. In the first analysis, I defined $3 \mathrm{DCs}$, where each particular DC was chosen in order to allocate an equal number of colony pairs to each DC. In the second analysis, I defined 5 DC with a constant size. Both analyses indicate whether a change in some spatial parameter can affect the results. These indices were plotted against the geographic distances to produce correlograms. For these spatial analyses, the $O, a, t^{b}$ alleles and the expected heterozygosity were used. A matrix of binary connection was used in the way described by Sokal and Oden (1978b) (with human blood groups in Eire) and Trexler (1988). This was due to the fact that we do not know the history of migrations among these cat colonies and because we consider that the gene flow between the colonies (caused by the relationship between man and cat) could happen in any direction and possibly not depending on the proximity of the colonies. For a single autocorrelation coefficient for all the colonies studied simultaneously, point pairs were weighted as the inverse square of their separation distance. To determine statistical significance for autocorrelation coefficients, the Bonferroni procedure was used (Oden, 1984). The application of $G_{\mathrm{ST}}$ and $F_{\mathrm{ST}}$ statistics needs the designation of populations, subpopulation or colony, which is often arbitrary (Ennos, 1985; Bos et al, 1986). In addition, the border between these units or the size of the units often makes the correct application of the cited statistics difficult. In contrast, SAA 
does not need a definition of subpopulation or colony, and is independent of the spatial scale level of the structure we want to analyse.

\section{RESULTS}

\section{Genetic differentiation and gene flow}

The genetic differentiation and gene flow statistics for the three $O, a, t^{b}$ alleles are summarized in table I. As we can see, the intercolony gene differentiation exhibited by $a\left(F_{\mathrm{ST}}^{\prime}=0.0183\right)$ and $t^{b}\left(F_{\mathrm{ST}}^{\prime}=0.048\right)$ is small. In other words, one colony has on average 98.2 and $95.2 \%$ of the total genic diversity found in the total cat population of Marseilles for the $a$ and $t^{b}$ alleles, respectively. The $a$ and $t^{b}$ allele frequencies do not show significant heterogeneity between the Marseilles cat colonies. In contrast, $O$ shows a more important gene frequency differentiation than the $a$ and $t^{b}$ alleles $\left(F_{\mathrm{ST}}^{\prime}=0.2015\right)$. Moreover, this $O$ gene frequency differentiation is significant $\left(\chi^{2}=72.14,8 d f, P<0.001\right)$. As the $F$-tests demonstrate, $t^{b}$ does not exhibit significantly more genetic heterogeneity than $a\left(F_{[6,8]}=1.27 \mathrm{NS}\right)$, but $O$ does exhibit significantly more heterogeneity than $a$ and $t^{b}\left(F_{[8,8]}=11.93\right.$, $P<0.001$ and $F_{[8,6]}=9.34, P<0.01$, respectively). The mean value obtained for the 3 alleles shows a significant $\bar{F}_{\mathrm{ST}}^{\prime}$ value (see table I), but if the $O$ allele is excluded, the mean value for the $a$ and $t^{b}$ alleles $\left(\bar{F}_{\mathrm{ST}}^{\prime}=0.033\right)$ is clearly not significant.

Table I. Analysis of genetic diversity and gene flow ${ }^{1}$ between the cat colonies studied by Dreux (1975) in Marseilles (France).

\begin{tabular}{lccccccrrr}
\hline Locus & $\mathrm{G}_{S T}$ & $\mathrm{~F}_{S T}^{\prime}$ & $\chi^{2}$ & $\mathrm{df}$ & $\mathrm{Dm}$ & $\mathrm{R}_{S T}$ & $\mathrm{Nm}$ & $\mathrm{Nm \alpha}$ \\
\hline Orange $(O)$ & 0.2043 & 0.2015 & $72.147^{*}$ & 8 & 0.0546 & 0.2888 & 0.990 & 0.783 \\
Non-agouti $(a)$ & 0.0213 & 0.0183 & 6.045 & 8 & 0.0090 & 0.0245 & 13.397 & 10.585 \\
Blotched $\left(t^{b}\right)$ & 0.0552 & 0.0488 & 7.721 & 6 & 0.0232 & 0.0681 & 4.866 & 3.575 \\
Mean value & 0.0936 & 0.0895 & $85.913^{*}$ & 22 & 0.0289 & 0.1271 & - & - \\
for 3 loci & \pm 0.0486 & \pm 0.0490 & - & - & 0.0116 & \pm 0.0708 & - & - \\
\hline
\end{tabular}

Direct values for the 3 loci: $N m=2.541 ; N m \alpha=1.960 .{ }^{*} P<0.001 .^{1}$ Symbols defined in text.

For the estimations of the gene flow, I found a similar situation. I obtained high theoretical estimates of $N m$ for the $a$ and $t^{b}$ alleles $\left(N m^{\prime}=13.4\right.$ and 4.9 , respectively), but the $N m$ value for $O\left(N m^{\prime}=0.99\right)$ was very small. So, as a first step, we can observe how the $O$ gene might seem strongly affected by an important founder effect, but the homogeneity of the $a$ and $t^{b}$ genes does not support this hypothesis at all. 


\section{Expected heterozygosity}

Table II shows the expected heterozygosity for the 9 colonies analyzed. The comparisons of the expected mean heterozygosity between all pairs of colonies using the Student's $t$-test are summarized in table III. Only one comparison out of the 36 possible combinations reached significance. The Anova applied to the expected mean heterozygosity set did not show significant heterogeneity (table IV), as confirmed by the Kruskal-Wallis $H$-test $\left(H^{\prime}=4.82,8 d f, 0.70<P<0.80\right)$. Thus, the founder effect does not seem to strongly influence the present results for heterozygosity. All the colonies show similar levels of heterozygosity, even those with very small samples $(n=19.88$ cats for the 9 colonies and $n=13.77$ cats, excluding the $E$ colony ( $n=72$ cats $)$ ).

Table II. Expected heterozygosity in Marseilles cat colonies.

\begin{tabular}{lccccccccc}
\hline Locus & \multicolumn{10}{c}{ Colonies } \\
\cline { 2 - 10 } & $A$ & $B$ & $C$ & $D$ & $E$ & $G$ & $H$ & $I$ & $J$ \\
\hline Orange & 0.415 & 0 & 0.169 & 0.351 & 0.019 & 0 & 0.471 & 0.433 & 0.497 \\
Non-agouti & 0.448 & 0.287 & 0.271 & 0.282 & 0.425 & 0.386 & 0.282 & 0.383 & 0.309 \\
Blotched & 0.102 & - & 0.452 & 0.265 & 0.436 & - & 0 & 0.368 & 0.367 \\
Mean & 0.322 & 0.144 & 0.298 & 0.299 & 0.294 & 0.193 & 0.251 & 0.394 & 0.391 \\
& $\pm 0.095 \pm 0.102 \pm 0.071$ & $\pm 0.023 \pm 0.118 \pm 0.136 \pm 0.118 \pm 0.017 \pm 0.047$ \\
\hline
\end{tabular}

Table III. Comparisons of the expected mean heterozygosity between pairs of Marseilles cat colonies using the Student's $t$-test.

\begin{tabular}{|c|c|c|c|c|c|c|c|c|c|}
\hline & $A$ & $B$ & $C$ & $D$ & $E$ & $G$ & $H$ & $I$ & $J$ \\
\hline A & - & 1.000 & 0.176 & 0.198 & 0.160 & 0.637 & 0.403 & 0.647 & 0.564 \\
\hline B & & - & 1.017 & 1.384 & 0.725 & 0.204 & 0.519 & 2.274 & 1.923 \\
\hline $\mathrm{C}$ & & & - & 0.021 & 0.024 & 0.583 & 0.291 & 1.139 & 0.944 \\
\hline D & & & & - & 0.041 & 0.719 & 0.347 & $2.885^{*}$ & 1.502 \\
\hline $\mathrm{E}$ & & & & & - & 0.441 & 0.220 & 0.726 & 0.662 \\
\hline G & & & & & & - & 0.254 & 1.377 & 1.234 \\
\hline $\mathrm{H}$ & & & & & & & - & 1.036 & 0.951 \\
\hline I & & & & & & & & - & 0.049 \\
\hline $\mathbf{J}$ & & & & & & & & & - \\
\hline
\end{tabular}

${ }^{*} P<0.05$.

\section{Phenetic and principal coordinates analyses}

A first graphic approximation on the spatial genetic relationships between the Marseilles cat colonies using a UPGMA phenetic analysis and with 2 different 
Table IV. Analysis of variance (Anova) of the expected heterozygosity means in Marseilles cat colonies.

\begin{tabular}{|c|c|c|c|c|c|}
\hline \multirow[t]{2}{*}{ Source } & \multicolumn{3}{|c|}{ Anova } & \multirow[t]{2}{*}{$\mathrm{F}$ ratio } & \multirow[t]{2}{*}{$\mathrm{F}$ probability } \\
\hline & $\mathrm{df}$ & Sum of squares & Mean squares & & \\
\hline Between colonies & 8 & 0.2771059 & 0.0346382 & 1.6580 & NS \\
\hline Within colonies & 16 & 0.3342541 & 0.0208908 & & \\
\hline Total & 24 & 0.6113601 & & & \\
\hline
\end{tabular}

genetic distances does not exhibit any special trend to cluster the neighbouring colonies (fig 2). Nevertheless, the UPGMA phenetic analyses with the Prevosti and the Cavalli-Sforza and Edwards distances show certain different relationships between the colonies. The PCA with the graphic matrix MST superimposed also shows the same tendency (fig 3 ). This means that there seems to exist a stronger tendency for neighbouring colonies to group together. This occurs for both genetic distances used.

A

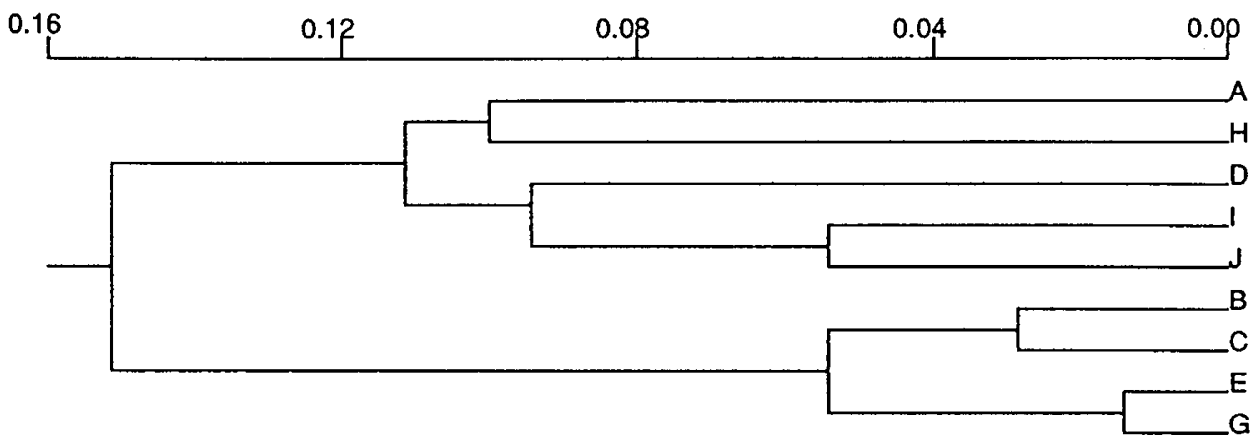

B

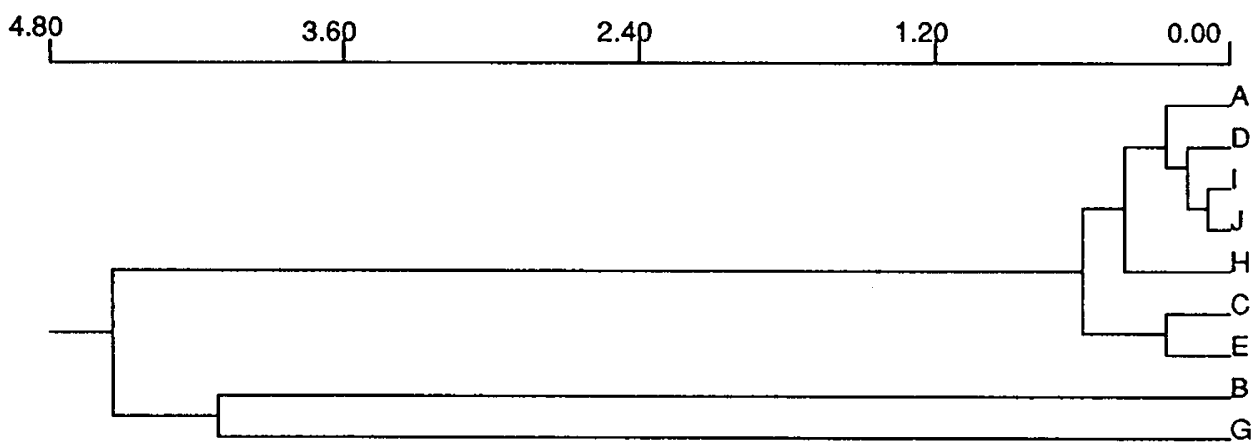

Fig 2. UPGMA phenetic analysis of Marseilles cat colonies: A with the Prevosti distance; $\mathbf{B}$ with the Cavalli-Sforza and Edwards distance. 


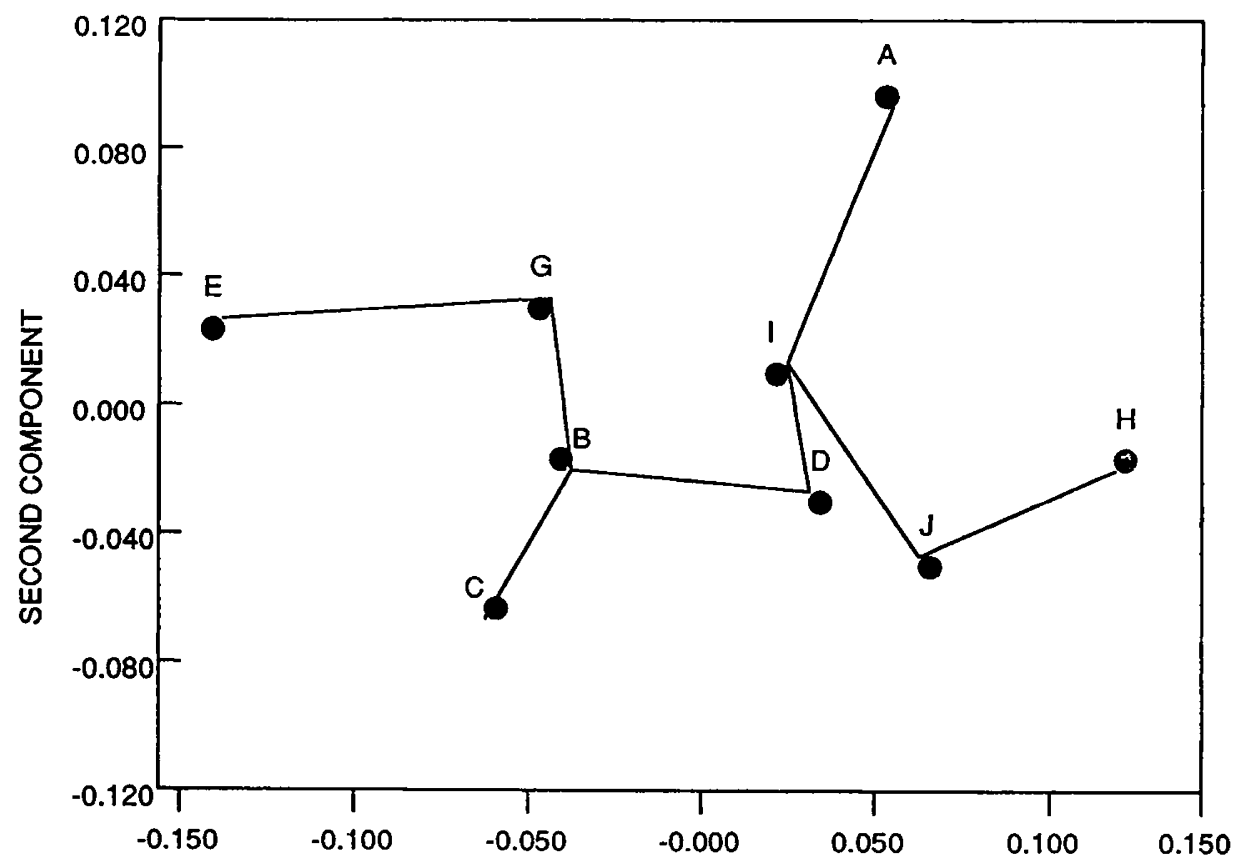

FIRST COMPONENT

Fig 3. PCA with MST superimposed for Marseilles cat colonies: first component $v s$ second component for the Prevosti distance.

\section{Mantel test}

Other approaches to understand the spatial relationships among these colonies were the correlations obtained between geographic and genetic distance matrices using the Mantel test. There are no significant associations between both types of matrices in either case. In the case of the Prevosti distance, all correlations are negative. For this distance, the geographic separation negatively explains between 4.38 and $8.23 \%$ of the genetic heterogeneity found (according to the different mathematical models). For the Cavalli-Sforza and Edwards distance, the correlations are positive, but not significant (between 3.35 and $9.12 \%$ of the genetic heterogeneity).

\section{Spatial autocorrelation analysis}

The most powerful methodological technique used to explain the spatial relationships between these colonies is the spatial autocorrelation. The application of the Moran's index as a single coefficient for all colonies simultaneously for the 3 alleles studied did not show any significant spatial structure $(O, I=-0.114, P=0.486$; $\left.a, I=-0.150, P=0.466 ; t^{b}, I=-0.071, P=0.448\right)$. Using 3 distance classes as 
defined in table $\mathrm{V}$, neither the allele nor the expected heterozygosity showed significant individual spatial autocorrelation coefficients. The 4 overall correlograms for $O, a$ and $t^{b}$ alleles and for the expected heterozygosity were also non-significant. The average correlogram for the 3 genes studied did not show any spatial trend $(-0.259,-0.008,-0.125)$. With 5 distance classes, only one coefficient out of the $20 I$ values was significant. The 4 overall correlograms for $O, a, t^{b}$ and expected heterozygosity were not significant. The average correlogram for the 3 alleles did not show any spatial trend $(-0.208,-0.293,0.222,-0.233,-0.012)$. Globally, spatial autocorrelation does not seem to exist for any of these 3 alleles or for the expected heterozygosity. In a large number of correlograms there seems to exist a disposition to 'crazy quilt' resembling that generated by Royaltey et al (1975). Most of the correlograms show random fluctuations between positive and negative values without a clear tendency to offer significantly more positive $I$ values at a short distance compared with those observed at longer distance. This poor autocorrelation suggests that there is a poor genetic substructuring of the Marseilles cat colonies for the 3 gene frequencies studied and for the expected heterozygosity.

Table V. Spatial autocorrelation analysis with the Moran's $I$ index for 3 alleles $(O, a$, $t^{b}$ ), for average coefficients and for the expected heterozygosity.

\begin{tabular}{|c|c|c|c|c|c|}
\hline \multirow[t]{2}{*}{ Distance class $(m)$} & \multicolumn{3}{|c|}{ Allele } & \multirow[t]{2}{*}{ Average } & \multirow[t]{2}{*}{ Heterozygosity } \\
\hline & $\mathrm{O}$ & $\mathrm{a}$ & $t^{b}$ & & \\
\hline \multicolumn{6}{|l|}{$A$} \\
\hline 1.947 & -0.192 & -0.065 & -0.519 & -0.259 & -0.237 \\
\hline 3.625 & 0.059 & -0.136 & 0.053 & -0.008 & 0.117 \\
\hline 6.169 & -0.242 & -0.174 & 0.040 & -0.125 & -0.255 \\
\hline $\begin{array}{l}\text { Global correlogram } \\
\text { probability }(p)\end{array}$ & 0.613 & 1.000 & 0.231 & NS & 0.377 \\
\hline \multicolumn{6}{|l|}{$B$} \\
\hline 1.234 & -0.446 & -0.207 & 0.030 & -0.208 & -0.148 \\
\hline 2.468 & 0.050 & -0.433 & -0.496 & -0.293 & -0.174 \\
\hline 3.701 & 0.147 & $0.481^{*}$ & 0.038 & 0.222 & 0.191 \\
\hline 4.935 & -0.387 & -0.419 & 0.143 & -0.233 & -0.037 \\
\hline 6.169 & -0.039 & 0.169 & -0.167 & -0.012 & -0.560 \\
\hline $\begin{array}{l}\text { Global correlogram } \\
\text { probability }(p)\end{array}$ & 0.849 & 0.207 & 0.350 & NS & 0.512 \\
\hline
\end{tabular}

Distance classes are identified by the upper limit only. $A$. Three distance classes with an equal number of colony pairs in each distance class. $B$. Five distance classes with constant size; ${ }^{*} p<0.05$. 


\section{DISCUSSION}

\section{Possible causes of genetic heterogeneity and spatial patterns}

Sokal and Oden (1978b) showed that 2 different concepts must be distinguished to explain the differentiation of a genetic variable distributed over a geographic area: statistical heterogeneity and geographic patterns. Statistical heterogeneity can be studied by different mathematical techniques (Anova, homogeneity $\chi$-square test, etc) while the geographic patterns can be analyzed using a spatial autocorrelation analysis. Statistical heterogeneity and patterns are mutually independent of each other. For this reason, we can analyze the 3 possible and logical combinations (Sokal and Oden, 1978b):

A Significant heterogeneity and significant spatial patterns: 1) migration between neighbouring populations; 2) founder effects with the establishment of new demes by relatively close founders; 3 ) selective agents in response to environmental gradients or patterned patches; and 4) systematic migration.

B Significant heterogeneity and absence of spatial patterns: 1) genetic drift; 2) founder effects with the founders coming with near equiprobability from entire array of colonies over the range of the population; and 3) selective agents and/or unpatterned patches.

C Homogeneity of means and absence of pattern (population's poor genetic substructuring): 1) high gene flow at random within the entire study area; 2) uniform selective pressures within entire study area (Ayala et al, 1971; Hebert, 1974).

With these premises and taking into account the global results for the 3 genes studied, we would find ourselves in case B. Therefore, we would have 3 possible causes to explain the gene distribution we have observed. The second cause would be in accordance with Dreux's (1975) statements, $i e$ frequent founder effects with the same probability over the range of the population. In other studies, this explanation has also been useful to explain the genetic structure of other organisms (Sokal and Oden, 1978b; Waser, 1987; Lopez-Alonso and Pascual-Requera, 1989). However, if we analyze each of these genes separately and the expected average heterozygosity, we observe that the situation changes. The $a$ and $t^{b}$ genes show neither significant statistical heterogeneity nor spatial autocorrelation. The same happens with the expected mean heterozygosity. In contrast, the $O$ gene shows significant statistical heterogeneity, but no spatial autocorrelation. Thus, the individualized analysis seems to dismiss this second cause as the global explaining factor of the allele distributions observed. The genetic drift and the founder effects with the same demographic parameters affect the 3 genes studied in the same way and should have the same effect on the whole genome. At least for the $a$ and $t^{b}$ alleles and for expected mean heterozygosity, case $\mathrm{C}$ above seems to be more acceptable. So, the 2 foreground agents would be: a) intense gene flow without following fixed routes; and b) uniform selective pressure. It is difficult to distinguish which of the 2 hypotheses is more likely. Moreover, the 2 hypotheses are not mutually exclusive and could be acting simultaneously.

An attempt to explain these observations from a selective point of view could be as follows. It has previously been postulated that the a and $t^{b}$ genes benefit 
from the urban effect (Todd, 1969, 1977, 1978; Clark, 1975, 1976). This selective cause could have induced the homogeneity of means found and the absence of autocorrelation for those 2 alleles in the cat colonies of Marseilles. On a small scale, the heterotic effect (Bulmer, 1973; Bush et al, 1987) for these genes should promote spatial homogeneity. However, there are examples of other towns where the urban selective effect might be at least as intense as in Marseilles ( $e g$, Barcelona, Palma in Majorca, Murcia in Spain, Rimini in Italy, Buenos Aires in Argentina, and Jerusalem and Tel-Aviv in Israel; Ruiz-Garcia, 1991, 1993ab) and where the $a$ and, especially, the $t^{b}$ alleles show a strong significant statistical heterogeneity. These examples make us doubt the existence of a uniform selective pressure within the urban environment or of a heterotic effect (or, at least, other evolutionary agents are superimposed on them). It would be strange if this happened in the city of Marseilles and not in other intensely urban towns. From a selective point of view, the $O$ gene could be submitted to some diversifying selective agent over heterogeneous patches unpatterned in the space. Nevertheless, there does not seem to be sufficient microenvironmental differences (at least they are very difficult to imagine in this case) between these different areas of Marseilles, which may have some selective influence on this gene.

All this taken into account, a neutral point of view could be taken to explain the different genetic heterogeneity shown for each gene. It is possible that each gene studied in this work was introduced into Marseilles at different historical moments and with different ecological and demographic parameters (effective population sizes $(\mathrm{Ne})$, migration rates per generation $(m)$, number of colonists $(K)$, and extinction rates per generation (eo)). Moreover, these different migrant genes could have been introduced following different models. For instance, Slatkin (1977) defined 4 population structures in terms of the source of the migrant individuals and in terms of the way in which new colonies were established. The 2 models of the source of migrant individuals are: a) Model I. Migrants move from an external source with a constant gene frequency to an infinite number of local colonies; b) Model II. Migrants are drawn at random from within a finite array of subdivided populations. For these 2 models, there are 2 different ways in which colonists might be chosen to found new colonies: a) migrant pool, where new colonists $(K)$ are a random sample from the entire population; and, b) propagule pool, where the new colonies are founded by choosing colonists at random from a single randomly chosen colony. If the 3 genes studied were introduced at different historical moments with different demographic parameters, different sources of migrants and different ways in which colonists were chosen, we should expect different $F_{\mathrm{ST}}$ values for each gene studied (Wade, and McCauley, 1988).

With all this in mind, $O$ is the unique allele that could be influenced by a strong founder effect in the Marseilles cat population. Nevertheless, the $a$ and $t^{b}$ data do not support this strong influence. Only in the case that the $O$ allele is neutral and that the $a$ and $t^{b}$ alleles are under uniform selective pressure, should the Dreux (1975) conclusion (importance of the founder effect) be certain.

\section{Gene flow and heterozygosity}

Trexler (1988) showed that if $N m>1$ (in an infinite island model) or $N m>4$ (in a stepping-stone model), the gene flow is enough to attenuate the genetic dif- 
ferentiation between populations balanced for migration and gene drift. According to the infinite island model, if $1<N m<0.5$, the genetic differentiation between populations is small but important in a stepping-stone model : $\mathrm{If} N m<0.5$, the populations are largely unconnected under any model of gene flow. The $N m$ values for $a$ and $t^{b}\left(N m^{\prime}=13.4\right.$ and 4.9 , respectively) are higher than 1 (and even 4 ). On the contrary, for the $O$ gene $\left(N m^{\prime}=0.99\right)$ the gene flow would be considerably smaller. As we can observe from the absence of spatial autocorrelation and from the absence of significant correlation between genetic and geographic distances with the Mantel test, we find a situation very similar to an island model where the effect of geographical distance seems non-significant (Cavalli-Sforza and Bodmer, 1981).

The analysis of the expected mean heterozygosity seems to confirm this model. The absence of autocorrelation and the homogeneity of the means confirm that stochastic processes are not extraordinarily important as evolutionary agents among the cat colonies studied in Marseilles (even though the average size of the samples is only 19 individuals). The same has been observed for other animals (Grant, 1980; Kennedy et al, 1987) but they differ from what has been observed in other mammals (Patton, 1972; Penney and Zimmerman, 1976). As can be observed, the average levels of heterozygosity of these 3 genes are high, and as has been proved by other studies, high gene flow maintains high levels of heterozygosity (Wheeler and Guries, 1982; Waples, 1987; Ruiz-Garcia, 1991) confirming the probable great importance of gene flow in this model. Even though the sizes of the colonies could be small, the fact that cat litters are strongly dispersed, spreading out from their original colony (either as a consequence of the intrinsic characteristics of their reproductive behaviour, or direct human action) and the subsequent integration into other reproduction units favours the maintenance of high mean heterozygosity values. The same was determined for Thomomys bottae (Patton and Feder, 1981).

Nevertheless, we do not know whether the gene flow occurs at the time of colony formation or between colonies that have been present for a long time.

\section{ACKNOWLEDGMENTS}

For different reasons, my infinite thanks to P Dreux (Paris, France), A Sanjuan (Vigo, Spain), AT Lloyd (Dublin, Ireland), KK Klein (Minnesota, USA), R Robinson (London, UK) and A Prevosti (Barcelona, Spain). My thanks also to BH Zimmermann (Michigan, USA) for help with the English syntax of this manuscript, and, especially to Diana Alvarez (Bogota DC, Colombia) for her valuable assistance.

\section{REFERENCES}

Ayala FJ, Powell JR, Dobzhansky T (1971) Polymorphism in continental and island populations of Drosophila willistoni. Proc Nat Acad Sci USA 68, 2480-2483

Bos M, Harmens H, Vrieling K (1986) Gene flow in plantago. I. Gene flow and neighborhood size in $P$ lanceolata. Heredity $56,43-54$

Bulmer MG (1973) Geographical uniformity of protein polymorphisms. Nature (Lond) $241,199-200$

Bush RM, Smouse PE, Ledig FT (1987) The fitness consequences of multiple-locus heterozygosity: the relationship between heterozygosity and growth rate in pitch pine (Pinus rigida Mill). Evolution 41, 787-798 
Cavalli-Sforza LL, Bodmer WF (1981) Genética de las poblaciones humanas. $942 \mathrm{p}$ Ediciones Omega, Barcelona

Cavalli-Sforza 'LL, Edwards AWF (1967) Phylogenetic analysis: models and estimation procedures. Evolution 21, 550-570

Chesser RK (1983) Genetic variability within and among populations of the black-tailed prairie dog. Evolution 37, 320-331

Clark JM (1975) The effects of selection and human preference on coat colour gene frequencies in urban cats. Heredity 35, 195-210

Clark JM (1976) Variations in coat colour gene frequencies and selection in cats of Scotland. Genetica 46, 401-412

Crow JF, Aoki K (1984) Group selection for a polygenic behavioural trait: estimating the degree of population subdivision. Proc Natl Acad Sci USA 81, 6073-6077

Dreux P (1975) Génétique de population des chats domestiques de Marseille (Bouchesdu-Rhône, France). Ann Génét Sél Anim 7, 23-33

Eanes WF, Koehn RK (1978) An analysis of genetic structure in the monarch butterfly, Danaus plexipus L. Evolution 32, 784-797

Ennos RA (1985) The mating system and genetic structure in a perennial grass, Cynosurus cristatus L. Heredity 55, 121-126

Gaines MS, Whittam TS (1980) Genetic changes in fluctuating vole populations: selective vs non-selective forces. Genetics $96,767-778$

Gower JC (1966) Some distance proporties of latent root and vector methods used in multivariate analysis. Biometrika 53, 325-338

Grant V (1980) Gene flow and the homogeneity of species populations. Biol Zbl99, 157-169

Gyllensten U (1985) Temporal allozyme frequency changes in density fluctuating populations of willow grouse (Lagopus lagopus L). Evolution 39, 115-121

Hebert PDN (1974) Enzyme variability in natural populations of Daphnia magna. I. Population structure in East Anglia. Evolution 28, 546-556

Kennedy PK, Kennedy ML, Beck ML (1987) Genetic variability in white-tailed deer (Odocoileus virginianus) and its relationship to environmental parameters and herd origin (Cervidae). Genetica 74, 189-201

Lopez-Alonso D, Pascual-Reguera L (1989) Population structure and pattern of geographic variation in Muscari comosum along its range of distribution. Genetica 78, 39-49

Mantel NA (1967) The detection of disease clustering and a generalized regression approach. Cancer Res 27, 209-220

Moran PAP (1950) Notes on continuous stochastic phenomena. Biometrika 37, 17-23

Nei M (1973) Analysis of gene diversity in subdivided populations. Proc Natl Acad Sci USA 70, 3321-3323

Nei M (1975) Molecular Population Genetics and Evolution. North-Holland Press, Amsterdam

Nei M (1978) Estimation of average heterozygosity and genetic distance from a small number of individuals. Genetics 89, 583-590

Oden N (1984) Assessing the significance of a spatial correlogram. Geogr Anal 16, 1-16

Patton JL (1972) Patterns of geographic variation in karyotype in the pocket gophers. Thomomys bottae (Eydoux and Gervais). Evolution 26, 574-586

Patton JL, Feder JH (1981) Microspatial genetic heterogeneity in pocket gophers: nonrandom breeding and drift. Evolution 35, 912-920

Penney DF, Zimmerman EG (1976) Genic divergence and local population differentiation by random drift in the pocket gopher genus Geomys. Evolution 30, 473-483

Prevosti A (1974) La distancia genética entre poblaciones. Miscellanea Alcobé. Publicacions de l'Universitat de Barcelona, 109-118 
Rohlf FJ (1970) Adaptive hierarchical clustering schemes. Systematic Zool 19, 58-82

Royaltey HH, Astrachan E, Sokal RR (1975) Tests for patterns in geographic variation. Geogr Anal 7, 369-395

Ruiz-Garcia M (1991) Más sobre la Genética de poblaciones de Felis catus en la costa Mediterránea Española: Un análisis de la Estructura Genética de las poblaciones naturales de gatos. Evol Biol 5, 227-283

Ruiz-Garcia M (1993a) Analysis of the evolution and genetic diversity within and between Balearic and Iberian cat populations. $J$ Hered $84,173-180$

Ruiz-Garcia M (1993b) Genetic structure and Evolution of different cat populations (Felis catus) in Spain, Italy, Argentina and Israel at microgeographical level: history and time and/or ecological and social factors and/or current population size? Evol Biol 7 (in press)

Slatkin M (1977) Gene flow and genetic drift in a species subject to frequent local extinction. Theor Popul Biol 12, 253-262

Slatkin M (1985a) Rare alleles as indicators of gene flow. Evolution 39, 53-65

Slatkin M (1985b) Gene flow in natural populations. Ann Rev Ecol Syst 16, 393-430

Sneath PH, Sokal RR (1973) Numerical taxonomy. Ed Freeman, San Francisco

Snedecor G, Irwin MR (1933) On the chi-square test for homogeneity. Iowa State J Science $8,75-81$

Sokal RR, Menozzi P (1982) Spatial autocorrelation of HLA frequencies in Europe support demic diffusion of early farmers. Am Nat 119, 1-17

Sokal RR, Oden NL (1978a) Spatial autocorrelation in biology. I. Methodology. Biol J Linn Soc 10, 199-228

Sokal RR, Oden NL (1978b) Spatial autocorrelation in biology. II. Some biological implications and four applications of evolutionary and ecological interest. Biol J Linn Soc 10, 229-249

Todd NB (1969) Cat gene frequencies in Chicago and other populations of the United States. J Hered 60, 273-277

Todd NB (1977) Cats and Commerce. Sci Amer 237, 100-107

Todd NB (1978) An ecological, behavioural genetic model for the domestication of the cat. Carnivore 1, 52-60

Trexler JC (1988) Hierarchical organization of genetic variation in the Sailfin Molly. Poecilia latipinna (Pisces: Poeciliidae). Evolution 42, 1006-1017

Wade MJ, McCauley DE (1988) Extinction and recolonization: their effects on the genetic differentiation of local populations. Evolution 42, 995-1005

Waples RS (1987) A multispecies approach to the analysis of gene flow in marine shore fishes. Evolution 41, 385-400

Waser NM (1987) Spatial genetic heterogeneity in a population of the montane perennial plant Delphinium nelsonii. Heredity 58, 249-256

Wheeler NC, Guries RP (1982) Population structure, genic diversity and morphological differentiation in Pinus contorta Dougl. Can J For P 595-606

Workman PL, Niswander JD (1970) Population studies on south western Indian tribes. II. Local genetic differentiation in the Papago. Amer J Hum Genet 22, 24-49

Wright S (1943) Isolation by distance. Genetics 28, 114-138

Wright S (1951) The genetical structure of populations. Ann Eugen 15, 323-354

Wright S (1965) The interpretation of population structure by $F$-statistics with special regard to systems of mating. Evolution 19, 395-420 